\title{
miR-875-5p exerts tumor-promoting function via down- regulation of CAPZA1 in esophageal squamous cell carcinoma
}

\author{
Nan Kang ${ }^{1,2}$, Yunwei Ou ${ }^{1}$, Guangchao Wang ${ }^{1}$, Jie Chen ${ }^{3}$, Dan Li ${ }^{\text {Corresp., } 1}$, Qimin Zhan ${ }^{\text {Corresp. }{ }^{1,3}}$ \\ ${ }^{1}$ State Key Laboratory of Molecular Oncology, National Cancer Center/National Clinical Research Center for Cancer/Cancer Hospital, Chinese Academy of \\ Medical Sciences and Peking Union Medical College, Beijing, China \\ 2 Department of Pathology, Peking University People's Hospital, Beijing, China \\ 3 Key laboratory of Carcinogenesis and Translational Research (Ministry of Education/Beijing), Laboratory of Molecular Oncology, Peking University Cancer \\ Hospital \& Institute, Beijing, China
}

Corresponding Authors: Dan Li, Qimin Zhan

Email address: eileenld@gmail.com, zhanqimin@bjmu.edu.cn

Esophageal squamous cell carcinoma (ESCC) is one of the leading causes of cancer deaths worldwide. Currently, efficient genetic markers for diagnosis and treatment of ESCC are lacking. MicroRNAs (miRNAs) are global genetic regulators that control cancer gene expression by binding to the 3'untranslated regions (3'UTRs) of targeting mRNAs. In addition, miRNAs function as oncogenes or tumor suppressors in the progression of tumors. In the current study, we found that hsa-miR-875-5p (miR-875-5p) exhibited amplification in ESCC according to the TCGA database. Then, xCELLigence Real-Time Cell Analyzer (RTCA)-MP system and colony formation assays were employed to detect cell proliferationand colony formationability. The results showed that miR-875-5p promoted the proliferation ESCC cells. Subsequently, transwell results indicated that miR-875-5p promoted the invasion and migration of ESCC cells. Furthermore, we showed that miR-875-5p was able to bind to CAPZA13'UTR, which contains the single nucleotide polymorphism (SNP), rs373245753, as reported in our previous study involving WGS and WES on ESCC. Subsequently, mRNA affinity pull-down assays verifiedthat the SNP disrupts miR-875-5p binding to CAPZA1. The current study is the first demonstration that miR-875-5p may function as an oncogene via down-regulation of CAPZAlexpression in ESCC. 
1

2

3

4

5

6

7
miR-875-5p exerts tumor-promoting function via down-regulation of $C A P Z A 1$ in esophageal squamous cell carcinoma

Nan Kang ${ }^{1,2}$, Yunwei Ou ${ }^{1}$, Guangchao Wang ${ }^{1}$, Jie Chen ${ }^{3}$, Dan $\mathrm{Li}^{1 *}$, Qimin Zhan ${ }^{1,3 *}$

${ }^{1}$ State Key Laboratory of Molecular Oncology, National Cancer Center/National Clinical

Research Center for Cancer/Cancer Hospital, Chinese Academy of Medical Sciences and Peking Union Medical College, Beijing, China

${ }^{2}$ Department of Pathology, Peking University People's Hospital, Beijing, China

${ }^{3}$ Key laboratory of Carcinogenesis and Translational Research (Ministry of Education/Beijing), Laboratory of Molecular Oncology, Peking University Cancer Hospital \& Institute, Beijing, China

Corresponding Author:

Dan Li, Cancer Hospital, Chinese Academy of Medical Sciences, No. 17 Panjiayuan Nanli, Chaoyang District, Beijing, China. eileenld@gmail.com +86010 87787496

Qimin Zhan, Peking University Cancer Hospital, 52 Fucheng Road, Haidian District, Beijing, China. zhanqimin@bjmu.edu.cn+8601087787496

\section{Abstract}

Esophageal squamous cell carcinoma (ESCC) is one of the leading causes of cancer deaths worldwide. Currently, efficient genetic markers for diagnosis and treatment of ESCC are lacking. MicroRNAs (miRNAs) are global genetic regulators that control cancer gene expression by binding to the 3'untranslated regions (3'UTRs) of targeting mRNAs. In addition, miRNAs function as oncogenes or tumor suppressors in the progression of tumors. In the current study, we found that hsa-miR-875-5p (miR-875-5p) exhibited amplification in ESCC according to the TCGA database. Then, xCELLigence Real-Time Cell Analyzer (RTCA)-MP system and colony formation assays were employed to detect cell proliferation and colony formation ability. The results showed that miR-875-5p promoted the proliferation of ESCC cells. Subsequently, transwell results indicated that miR-875-5p promoted the invasion and migration of ESCC cells. Furthermore, we showed that miR-875-5p was able to bind to CAPZA1 3'UTR, which contains the single nucleotide polymorphism (SNP), rs373245753, as reported in our previous study 
34 involving WGS and WES on ESCC. Subsequently, mRNA affinity pull-down assays verified

35 that the SNP disrupts miR-875-5p binding to CAPZA1. The current study is the first

36 demonstration that miR-875-5p may function as an oncogene via down-regulation of CAPZA1

37 expression in ESCC.

38

39

40

41

42

43

44

45

46

47

48

49

50

51

52

53

54

55

56

57

58

59

60

61

62

63

64

65

66

\section{Introduction}

Esophageal cancer is one of the most aggressive cancers worldwide and is categorized into two subtypes: esophageal adenocarcinoma (EAC); and esophageal squamous cell carcinoma (ESCC) (Pennathur et al. 2013). Approximately 70\% of the worldwide cases of ESCC occur in China, which is characterized by late detection and widespread metastases (Lin et al. 2010;

Pennathur et al. 2013). Like other common cancers, ESCC is a complex trait caused by genetic and environmental factors (Engel et al. 1991; Pennathur et al. 2013).

MicroRNAs (miRNAs) are a class of RNA molecules, approximately 22nt in length, that regulate gene expression through base pairing with the 3'UTRs of target mRNAs, resulting in mRNA cleavage or translation repression (Bartel. 2014 ; Lee \& Vasudevan. 2013). Recent studies have shown that miRNAs are aberrantly expressed in many human cancers and function as oncogenes or tumor suppressors in the initiation, development, and metastasis of human carcinomas (Chen. 2005; Esquela-Kerscher \& Slack. 2006 ; Nohata et al. 2013). It has been reported that Let-7c functions as a metastasis suppressor by targeting MMP11 and $P B X 3$ in colorectal cancer (Han et al. 2012). Furthermore, miRNA-424 may function as a tumor suppressor in endometrial carcinoma cells by targeting E2F7 (Quan et al. 2015). It has also been reported that miR-223-3p has a tumor-promoting role in head and neck squamous cell carcinoma (Bozec et al. 2017). Indeed, miR-875-5p is amplified 6\% and 5\% in EAC and ESCC from the TCGA database, respectively. There are several studies that have reported that miR-875-5p has an important role in tumor progression. Specifically, miR-875-5p promotes the invasion of lung cancer cells by inhibiting SATB2 (Wang et al. 2017). Up-regulation of miR-875-5p induces poorly differentiated thyroid carcinoma (PDTC) cell proliferation and reduces apoptosis and radioiodine uptake in vitro by down-regulating NIS (Tang et al. 2019), however, a limited number of studies have focused on the function of miR-875-5p in ESCC. We conducted a series of functional assays to assess the effects of miR-875-5p on ESCC cell lines.

It has been reported that approximately $30 \%$ of human genes are regulated by miRNAs (Carthew. 2006). We used TargetScan (Lewis et al. 2003) and miRanda (John et al. 2005) 
67 databases to predict the downstream genes of miR-875-5p. Interestingly, we found that miR-875-

$685 \mathrm{p}$ targeted the CAPZA1 3'UTR containing the single nucleotide polymorphism (SNP),

69 rs373245753, which we identified in our previous study on WGS and WES in ESCC (Song et al.

70 2014). CAPZAl encodes the $\alpha$ subunit of the F-actin capping protein, which binds to the barbed

71 ends of actin filaments and modulates nucleation of actin polymerization (Tsugawa et al. 2018).

72 Although $C A P Z A 1$ has been reported to have ectopic expression in neuroblastoma, malignant

73 melanoma, and gastric, liver, gastric, and breast cancers (Deng et al. 2017; Lee et al. 2013; Lo et

74 al. 2007; Yu et al. 2011), little is known regarding the specific functions of CAPZA1 in ESCC.

75 The miRNAs that target the 3'UTR of the corresponding genes and the seed regions are highly-

76 conserved evolutionarily (Chen \& Rajewsky. 2006). SNPs in miRNA target sites in the 3'UTRs

77 of mRNA represent a specific class of functional polymorphisms that may lead to gene

78 expression alterations by disrupting miRNA-target gene binding (Zhang et al. 2011). Therefore,

79 the purpose of this study was to determine whether miR-875-5p has a tumor-promoting function

80 via down-regulation of CAPZA1 and if the SNP has the potential disrupt the binding of miR-875-

$815 \mathrm{p}$ to $C A P Z A 1$ in ESCC.

82

83 Materials \& Methods

84

85 Cell culture and treatment

86 Human ESCC cell lines, YSE2, KYSE30, KYSE70, KYSE140, KYSE150, KYSE180,

87 KYSE410, KYSE450, KYSE510, COLO680 were provided by Professor Y. Shimada of Kyoto

88 University. YSE2, KYSE30, KYSE70, KYSE140, KYSE180, KYSE410, KYSE450, KYSE510,

89 COLO680 were cultured in 90\% RPMI1640 medium, with 10\% fetal bovine serum and

90 antibiotics, at $37^{\circ} \mathrm{C}, 5 \% \mathrm{CO}_{2}$; KYSE150 was cultured in the medium of 1:1 mixture of Ham's

91 F12 and RPMI-1640 containing 2\% FBS and antibiotics at humidified atmosphere with $37^{\circ} \mathrm{C}$, $925 \% \mathrm{CO}_{2}$.

93 Stable and transient transfection

94 Stable recombinant plasmids over-expressing $C A P Z A 1(T)$ and $C A P Z A 1(G)$ by lentiviral

95 infection and matched control vectors were constructed by Obio Technology Co. Ltd (Shanghai,

96 China). Plasmids over-expressing CAPZA1 CDS and matched control vectors pcDNA3.1were

97 constructed by Generay Biotech Co. Ltd (Shanghai, China). The target genes [CDS-3'UTR(T)

98 and CDS-3'UTR(G)] were inserted into the lentiviral vector (H145 pLenti-EF1a-EGFP-F2A- 
99 Puro-CMV-MCS). Luciferase pGL3 overexpression vectors [3'UTR(T) and 3'UTR(G)] and

100 pGL3 control plasmids were constructed by Generay Biotech Co. Ltd (Shanghai, China). miR-

101 875-5p mimics, miR-875-5p inhibitors, biotinylated miR-875-5p, and matched negative controls

102 (NCs) were synthesized by Guangzhou RiboBio Co. Ltd. (Guangzhou, China). For stable

103 transfection, cells at 70\%-80\% density were infected with lentivirus using Polybrene in serum-

104 free medium, then stable expressing cells were selected with an optimal concentration of

105 puromycin. For transient transfection or co-transfection, cells were transfected in serum-free

106 medium using Lipofectamine2000 following the manufacturer's protocol (Invitrogen, Carlsbad,

107 California, USA) when 70\%-80\% confluence was reached. The cells were then harvested and

108 followed by PCR or Western blot analysis.

109 Cell proliferation assays

110 As previously descripted, cell proliferation was detected by using the xCELLigence Real-

111 Time Cell Analyzer (RTCA)-MP system (Acea Biosciences/Roche Applied Science). 2,000cells

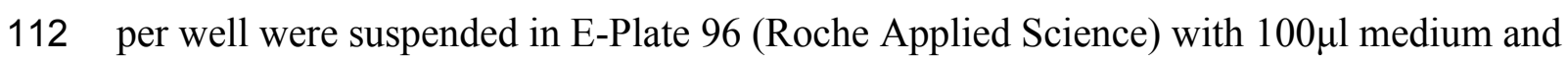

113 monitored in real time for $96 \mathrm{~h}$. Cell index was read automatically every $15 \mathrm{~min}$ and the recorded

114 growth curve were shown as cell index SD.

115 The colony formation assays were employed to test the colony formation ability of cells.

116 500-600 cells were seeded per well in 60mm plates and grown for 10-14 days. Then cells were

117 fix with methanol for $15 \mathrm{~min}$ and stained with $1 \%$ crystal violet-acetic acid solution for $20 \mathrm{~min}$,

118 colonies were visualized and quantitated by G:box (Syngene).

119 Invasion and migration assays

120 A Matrigel ${ }^{\mathrm{TM}}$ invasion chamber (BD Biosciences, Bedford, MA, USA) was used to evaluate

121 the migratory activity of ESCC cells. A total of $3 \times 10^{4}$ cells $/ \mathrm{ml}$ were suspended with serum-free

122 RPMI basal medium and seeded in a 24-well chamber, then filled with 600-800 $\mu$ l of RPMI-

1231640 medium with 20\% FBS per well beneath the chamber. After overnight incubation, the cells

124 which had migrated through the Matrigel ${ }^{\mathrm{TM}}$ membrane were fixed with methanol and stained

125 with $1 \%$ crystal violet-acetic acid solution for $20 \mathrm{~min}$.

126 For invasion assays, Matrigel ${ }^{\mathrm{TM}}$ matrix solution (1\% Matrigel $^{\mathrm{TM}}$ matrix diluted with serum-

127 free RPMI basal medium) was prepared, the plates were incubated for $2 \mathrm{~h}$, and then invasive

128 activity was detected as described above. The number of invasive and migrating cells were

129 quantified by fluorescence microscopy.

130 DNA, RNA extraction and quantitative real-time PCR 
131

132

133

134

135

136

137

138

139

140

141

142

143

144

145

146

147

148

149

150

151

152

153

154

155

156

157

158

159

160

161

162

Total DNA of cells was isolated by extraction kit according to the standard procedure (Tiangen, Beijing, China). Total RNA of cells was extracted with TRIzol reagent according to the standard procedure. Reverse transcription was performed by using Superscript II-reverse transcriptase kit (Invitrogen) following the manufacturer's instructions. The real-time PCR was performed in triplicate with the Premix Ex Taq kit (Takara) and a 7300 real-time PCR system (Life Technologies) according to manufacturer's instructions. Thermal cycling conditions were as follows: the first step, $95^{\circ} \mathrm{C}$ for $30 \mathrm{~s}$ and the ensuing $40 \mathrm{cycles}, 95^{\circ} \mathrm{C}$ for $5 \mathrm{~s}, 65^{\circ} \mathrm{C}$ for $31 \mathrm{~s}$, and melt curve step: $95^{\circ} \mathrm{C}$ for $15 \mathrm{~s}, 65^{\circ} \mathrm{C}$ for $1 \mathrm{~min}, 95^{\circ} \mathrm{C}$ for $15 \mathrm{~s}$. The PCR primers were provided by Invitrogen. GAPDH and U6 mRNA was employed as an endogenous control for mRNA. 3'UTR primers for PCR :

\section{F:5' GCCTCATGGAATACTGTTGAACC 3';}

\section{R:5' GGATAGATCACTCTCTCACC 3'。}

\section{Western blotting analysis}

Transfected cells were collected using lysis buffer $(1 \times \mathrm{PBS}+4 \%$ NP-40 $+0.2 \%$ proteinase inhibitor) and lysed by centrifugation at $12,000 \mathrm{rpm}$ for $20 \mathrm{~min}$ at $4{ }^{\circ} \mathrm{C}$. The supernatants were added with $2 \times$ SDS-PAGE sample loading buffer and boiled for $5 \mathrm{~min}$. Eighty micrograms of protein was fractionated by SDS-PAGE, then transferred to polyvinylidene difluoride membranes. The membranes were incubated with relative primary antibodies overnight at $4^{\circ} \mathrm{C}$, then secondary antibodies were incubated and quantified using Image Quant software (GE Healthcare Biosciences, Pittsburg, PA, USA).

\section{Biotin-labeled pull-down assays}

Biotinylated miR-875-5p (Guangzhou RiboBio Co, Ltd, China) pull-down assay with target mRNAs was performed as described(Christoffersen et al. 2009; Shi et al. 2013; Wynendaele et al. 2010). Cells were transfected with control miRNA and biotin-labeled miR-875-5p and wholecell lysates were harvested. Simultaneously, Streptavidin beads (Invitrogen) were coated with $10 \mu \mathrm{l}$ per sample yeast tRNA (Ambion) and incubated $2 \mathrm{~h}$ at $4{ }^{\circ} \mathrm{C}$. Then the beads were washed with $500 \mu 1$ lysis buffer three times and resuspended with $50 \mu 1$ lysis buffer. Sample lysates were mixed with pre-coated beads $\left(50 \mu \mathrm{l}\right.$ per sample) and incubated with rotator overnight at $4{ }^{\circ} \mathrm{C}$. Beads were pellet down by centrifugation at $5,000 \mathrm{rpm}$ for $1 \mathrm{~min}$ at $4{ }^{\circ} \mathrm{C}$ to remove unbound materials and then washed five times with $500 \mu \mathrm{l}$ ice-cold lysis buffer. Next, $750 \mu \mathrm{l}$ of TRIzol (Invitrogen) and $250 \mu 1$ nuclease-free water was added to both input and pull-down samples to isolate RNA. Finally, qPCR was employed to detect the expression ratio. 
163

164

165

166

167

168

169

170

171

172

173

174

175

176

177

178

179

180

181

182

183

184

185

186

187

188

189

190

191

192

193

194

\section{Statistical analysis}

GraphPad Prism v.5 software (GraphPad Software, Inc., La Jolla, CA, USA) and R version 4.0.2 software were used for statistical analyses. Data of colony numbers and mRNA expression levels of CAPZA1 were analysed by ANOVA. Data of colony formation, cell invasion and migration numbers of miR-875-5p, luciferase activity and the enrichment of CAPZA1 mRNAs were analysed by Student's t-test (two-tailed). Statistical differences are presented as the mean \pm standard deviation $(\mathrm{SD})$. A p value $<0.05$ was considered statistically significance.

\section{Results}

\section{miR-875-5p promoted cell proliferation and metastasis of ESCC cells}

Given that miRNAs can function as oncogenes or tumor suppressors in the progression of human cancers (Chen. 2005; Esquela-Kerscher \& Slack. 2006; Nohata et al. 2013), we first assessed the functions of miR-875-5p in ESCC cells. According to the TCGA and cBioProtal for Cancer Genomics database, we found that the gene which miR-875-5p encodes was amplified $6 \%$ and 5\% in EAC and ESCC, respectively, while approximately $1 \%$ were deleted in EAC and ESCC (Figure 1A). To determine the function of miR-875-5p in ESCC, we first introduced miR875-5p mimics and miR-875-5p negative control(NC) into ESCC cells, then we performed colony formation and transwell assays in KYSE180 and KYSE510 cells. As shown in Figure 1B to $\mathrm{G}$, the expression of miR-875-5p significantly increased colony formation of ESCC cells compared with NC transfected cells, indicating that miR-875-5p promoted the proliferation ability of ESCC cells. In transwell assays, miR-875-5p markedly enhanced the migration and invasion of ESCC cells compared with NC group in KYSE180 and KYSE510 cells (Figure 1H to S), which indicated that miR-875-5p facilitated metastasis of ESCC cells.

\section{miR-875-5p targeted the $C A P Z A 1$ 3'UTR containing the $T>G$ alteration at rs373245753}

Because SNPs may affect the interactions between miRNAs and their target genes, SNPs are thought to interfere with the mRNA expression of target genes by perturbing miRNAmediated gene regulation (Chen et al. 2008). We used TargetScan database and predicted that miR-875-5p targeted the CAPZA1 3'UTR containing the $\mathrm{T}>\mathrm{G}$ alteration at rs373245753 (Figure 2A), which was show in our previous study involving WGS and WES on ESCC (Song et al. 2014). CAPZA1 is located at chromosome 1 in humans with a length of 52167bp (Figure 2B). In addition, we employed a pair of PCR primers based on the 3'UTR and performed sequencing of 
195 the amplification products in 10 ESCC cell lines (YSE2, KYSE30, KYSE70, KYSE140,

196

197

198

199

200

201

202

203

204

205

206

207

208

209

210

211

212

213

214

215

216

217

218

219

220

221

222

223

224

225

226 KYSE150, KYSE180, KYSE410, KYSE450, KYSE510, and COLO680). We showed that the $\mathrm{T}>\mathrm{G}$ change at rs373245753 in the 3'UTR did not exist in these ESCC cell lines, indicating the need to heterogeneously-express the rs373245753 of 3'UTR in ESCC cells for further study (Figure 2C). Then, the full length of CAPZA1 3'UTR fragments containing the rs373245753 T or $\mathrm{G}$ allele were cloned into the luciferase reporter vector, pGL3, to compare the luciferase activities between the two alleles (Figure 2D). The pGL3 vectors containing the rs373245753 T or G allele of the CAPZA1 3'UTR were co-transfected in parallel with NC and miR-875-5p mimic to KYSE180 cells and luciferase activity was assayed. As shown in Figure 2E, for the $p G L 3-C A P Z A 1(T)$ construct, the miR-875-5p mimic significantly reduced luciferase activity compared with $\mathrm{NC}$, while no difference was observed in the $p G L 3-C A P Z A 1(G)$ group.

Luciferase activity was measured and normalized to firefly luciferase and the reference is Ranilla luciferase. These findings indicated that miR-875-5p directly targeted the CAPZA1 3'UTR(T), and negatively regulated $C A P Z A 1$ expression, while the variant allele attenuated these effects, thus allowing increased $C A P Z A 1$ expression in the presence of this variant allele.

\section{$C A P Z A 1(T)$ decreased the proliferation of ESCC cells and the function of CAPZA1 CDS} was not reversed by the mimic of miR-875-5p

Because the specific functions of CAPZA1 in ESCC have not been reported, we first determined the functions of $C A P Z A 1(T)$ and $C A P Z A 1(G)$ in ESCC. Cells were stably overexpressed with $C A P Z A 1(T)$ and $C A P Z A 1(G)$ by lentiviral infection and we further assessed the functions in KYSE180 and KYSE510 cells. Cell proliferation ability was detected using an xCELLigence Real-Time Cell Analyzer (RTCA)-MP system (Roche, Basel, Switzerland) and growth curves showed that $C A P Z A 1(T)$ reduced the rate of cell proliferation in KYSE180 and KYSE510 cell lines, whereas $C A P Z A 1(G)$ substantially abolished these effects (Figure $3 \mathrm{~A}$ and B). Colony formation abilities in both KYSE180 and KYSE510 cells were markedly suppressed by $C A P Z A 1(T)$ overexpression, but substantially increased in the $C A P Z A 1(G)$ overexpression cell lines (Figure $3 \mathrm{C}$ to $\mathrm{J}$ ). Furthermore, we detected the function of CAPZA1 CDS in ESCC cells. Cells were overexpressed with $C A P Z A 1 C D S$ and cell proliferation ability were assessed in KYSE180 cells. Cell growth curves and colony formation assays showed that CAPZA1 CDS significantly reduced the rate of cell proliferation in KYSE180 cells (Figure 3K to N). Additionally, we wondered that whether the suppressive effect was reversed by miR-875-5p. Cells were co-transfected with CAPZAl CDS and miR-875-5p, then cell growth curves and 
227 colony formation assays showed that the function of $C A P Z A 1 C D S$ was not reversed by miR-

228

229

230

231

232

233

234

235

236

237

238

239

240

241

242

243

244

245

246

247

248

249

250

251

252

253

254

255

256

257

258

$875-5 \mathrm{p}$ (Figure $3 \mathrm{O}$ to $\mathrm{R}$ ). These results suggested that CAPZA1 (T) decreased the proliferation of ESCC cells and the function of CAPZA1 CDS was not reversed by the mimic of miR-875-5p.

\section{miR-875-5p differentially regulated $C A P Z A 1$ expression in the presence of the SNP,} rs373245753 T

miRNAs can regulate gene expression and generate mRNA cleavage or translation repression by base pairing with their target mRNAs (Bartel. 2004; Lee \& Vasudevan. 2013). To determine whether miR-875-5p preferentially regulates $C A P Z A 1$ protein and mRNA levels of the $C A P Z A 1(T)$ and $C A P Z A 1(G)$ transcripts, pGL3 vectors containing the rs373245753 $\mathrm{T}$ or $\mathrm{G}$ of the CAPZA1 3'UTR and miR-875-5p mimic were co-transfected into KYSE180 and KYSE510 cells. We found that the protein levels were markedly reduced in CAPZA1(T) cells compared to CAPZA1(G) and controls in KYSE180 and KYSE510 cells, which suggested that miR-875-5p might bind to $C A P Z A(T)$ and represses the protein expression of $C A P Z A 1$ (Figure 4A and B). In addition, $\mathrm{qPCR}$ assays showed that miR-875-5p could target $C A P Z A 1(T)$ and suppressed CAPZA1 mRNA levels in KYSE180 and KYSE510 cells (Figure 4C and D). These observations indicated that miR-875-5p targets $C A P Z A 1(T)$ and negatively regulates $C A P Z A 1 \mathrm{mRNA}$ expression.

\section{The SNP, rs373245753 G, disturbed the binding of miR-875-5p and $C A P Z A 1 \mathrm{mRNA}$}

Increasing evidence has revealed that SNPs in the 3'UTRs of genes targeted by miRNAs can disturb or obstruct miRNA binding and consequently influence regulation of target genes, which might be associated with cancer (Sethupathy \& Collins. 2008). To determine whether the SNP, rs373245753 $\mathrm{T}>\mathrm{G}$, influences the binding of miR-875-5p and CAPZA1 mRNA, RNA affinity pull-down assays were performed (Christoffersen et al. 2009; Shi et al. 2013 ; Wynendaele et al. 2010). The pGL3 vectors containing the rs373245753 T or G allele of the CAPZA1 3'UTR were co-transfected with control or biotin-labeled miR-875-5p into KYSE180 and KYSE510 cells. Cell lysates were incubated with streptavidin-coated beads. RNA was harvested from the pull-down materials and amplified with CAPZA1 by qPCR. A biotin-labeled scrambled miRNA served as the control in these experiments. Firstly, qPCR assays were performed to measure the levels of pull-down and input $C A P Z A 1 \mathrm{mRNA}$ in the materials pulled down by biotin-miR-875-5p in ESCC cell lines(Figure 5A to D). We found that CAPZA1(T) was markedly elevated pulled down by biotin-miR-875-5p than $C A P Z A 1(G)$ groups, which indicated that the SNP would disturbed the binding of miR-875-5p and CAPZA1 mRNA (Figure 5A and 
259

260

261

262

263

264

265

266

267

268

269

270

271

272

273

274

275

276

277

278

279

280

281

282

283

284

285

286

287

288

289

290

B). Subsequently, the levels of CAPZA1 mRNA were significantly enriched in the pull-down material isolated from KYSE180 and KYSE510 cells following co-transfection biotin-labeled miR-875-5p with CAPZA1(T) compared to CAPZA1(G). We obtained that CAPZA1(T) were more highly bound with biotin-labeled miR-875-5p than $C A P Z A 1(G)$ (Figure 5E and F). Taken together, these results illustrated that the SNP, rs373245753 T $>\mathrm{G}$, disturbed the binding of miR875-5p and CAPZA1 mRNA.

\section{Discussion}

ESCC has one of the highest incidences among cancers in China. Currently, there are the clinical approaches for early diagnosis and efficient therapies are limited due to the incomplete understanding of the underlying mechanism(s) of ESCC(I et al. 2015). Recent studies have demonstrated that miRNAs can influence almost every genetic pathway and regulate diverse biological processes, including the initiation and progression of ESCC (Chen 2005; EsquelaKerscher \& Slack. 2006 ; Kim \& Cho. 2010; Lu et al. 2005).

It has been reported that mutations or abnormal expression of miRNAs are associated with various cancers and miRNAs can function as tumor-promoting genes or tumor suppressors (Chen. 2005; Esquela-Kerscher \& Slack.2006; Nohata et al. 2013). According to the TCGA database, we found that miR-875-5p is amplified 6\% with $1 \%$ deletion in ESCC. Although it has been confirmed that miR-875-5p exerts tumor suppressor function via down-regulation of EGFR in colorectal carcinoma (CRC) (Zhang et al. 2016), the specific functions and relevant machinery of miR-875-5p in ESCC have not been elucidated. This finding prompted us to conduct a series of functional assays to assess the effects of miR-875-5p in ESCC cells. We observed that miR$875-5 \mathrm{p}$ increased the ability of cells to proliferate, migrate, and invade. Then, we investigated the downstream gene of miR-875-5p using public databases, and unexpectedly found that miR-8755p targeted CAPZA1 3'UTR containing the SNP, rs373245753(Lewis et al. 2003; John et al.2005), which was identified in our previous study involving WGS and WES in ESCC (Song et al. 2014).

There is mounting evidence that SNPs in miRNA-target gene interactions might affect miRNA-mediated gene regulation by disrupting the binding of miRNA to target mRNA (Zhang et al. 2011), and even contribute to cancer development (Landi et al. 2008; Harris et al. 2010). For example, the SNP in the KIT 3' UTR disrupts a miR-221/222 binding site in gastrointestinal 
291 stromal tumors (Ravegnini et al. 2019). The SNP in miR-146a is associated with decreased 292 expression of ETS1 (Wei et al. 2014). The SNP in a miRNA-1827 binding site in MYCL1 alters 293 MYCL1 expression, which is associated with small-cell lung cancer (Xiong et al. 2011). The 294 miRNA binding site in the SNP affects $I L 23 R$ expression and is associated with breast cancer 295 (Wang et al. 2012). In this study, we verified that miR-875-5p could directly target the CAPZA1 296 3'UTR, leading to decreased CAPZA1 expression, while the variant allele disturbed the binding 297 of miR-875-5p to the CAPZA1 3'UTR. Furthermore, for the first time we showed that miR-875$2985 \mathrm{p}$ functions as an oncogene by down-regulating CAPZAl in ESCC. Because the specific 299 functions of CAPZA1 in ESCC have not been elucidated, this study also demonstrated that 300 CAPZA1 (T) negatively regulated the proliferation and metastasis of ESCC cells, while 301 CAPZA1 $(G)$ abrogated the suppressive ability. Additionally, we demonstrated that CAPZA1 CDS 302 alone can directly inhibit the malignant phenotype of esophageal cancer, while miR-875-5p 303 couldn't reverse the suppressive effect of CDS on malignant phenotype of esophageal cancer.

304 These results suggested that the miR-875-5p directly targeted CAPZA1 3'UTR(T), and 305 consistently, the SNP rs373245753 $\mathrm{T}>\mathrm{G}$ could influence the binding of miR-875-5p and 306 CAPZA1 3'UTR(T), which indicated that miR-875-5p has a tumor-promoting function by down307 regulation of CAPZA1 in ESCC.

In above, the current study first demonstrated that miR-875-5p promoted the proliferation 309 and metastasis of ESCC cells, probably through down-regulation of CAPZA1 expression. Moreover, the SNP, rs373245753, within the CAPZA1 3'UTR interfered with miR-875-5p binding to CAPZA1 mRNA. Based on these findings, it is reasonable to propose that miR-875-5p has as a tumor-promoting gene in ESCC, which might highlight the potential of miRNA profiling in cancer diagnosis. Because ESCC is one of the most aggressive cancers with a very poor prognosis, it is important to clearly understand the specific genetic factors for the 316 progression of ESCC, which may facilitate the development of diagnostic and therapeutic approaches.

\section{Conclusions}

In conclusion, we demonstrated that miR-875-5p functions as a tumor-promoting gene via down-regulation of CAPZA1 in ESCC cells. These findings highlight the importance of miR- 
322

323

324

325

326

327

328

329

330

331

332

333

334

335

336

337

338

339

340

341

342

343

344

345

346

347

348

349

350

351

352

353

354

355

356

357

358

359

360

361

362

363

364

365

366

875-5p in the development of ESCC and suggest the potential of this miRNA as a biomarker in cancer diagnosis.

\section{Acknowledgements}

Thanks to Professor Y. Shimada of Kyoto University for the providing of ESCC cell lines and to the Central Laboratory of Cancer Hospital of Chinese Academy of Medical Sciences for the instrument support.

\section{References}

Bartel DP. 2004.MicroRNAs: Genomics, Biogenesis, Mechanism, and Function. Cell 116:0-297.

Bozec A, Zangari J, Butori-Pepino M, Ilie M, and Vouret-Craviari V. 2017. MiR-223-3p inhibits angiogenesis and promotes resistance to cetuximab in head and neck squamous cell carcinoma. Oncotarget 8:57174-57186.

Carthew RW. 2006. Gene regulation by microRNAs. Current Opinion in Genetics \& Development 16:0-208.

Chen CZ. 2005. MicroRNAs as Oncogenes and Tumor Suppressors. New England Journal of Medicine 302:1-12.

Chen K, and Rajewsky N. 2006. Natural selection on human microRNA binding sites inferred from SNP data. Nature Genetics 38:1452-1456.

Chen K, Song F, Calin GA, Wei Q, Hao X, and Zhang W. 2008. Polymorphisms in microRNA targets: a gold mine for molecular epidemiology. Carcinogenesis 29:1306-1311.

Christoffersen NR, Shalgi R, Frankel LB, Leucci E, and Lund AH. 2009. P53-independent upregulation of miR-34a during oncogene-induced senescence represses MYC. Cell Death \& Differentiation 17:236-245.

Deng H, Li C, and Zheng S. 2017. CAPZA1 modulates EMT by regulating actin cytoskeleton remodelling in hepatocellular carcinoma. Journal of Experimental \& Clinical Cancer Research 36:1-9.

Engel LS, Chow W-H, Vaughan TL, Gammon MD, Risch HA, Stanford JL, Schoenberg JB, Mayne ST, Dubrow R, and Rotterdam H. 1991.Population Attributable Risks of Esophageal and Gastric Cancers. Journal of the National Cancer Institute 95:1404-1413.

Esquela-Kerscher A, and Slack FJ. 2006. Oncomirs - microRNAs with a role in cancer. Nature Reviews Cancer 6:259-269.

Essadi I, Lalya I, and Mansouri H. 2015. Esophageal carcinoma. New England Journal of Medicine 372:1470-1473.

Han HB, Gu J, Zuo HJ, Chen ZG, and Zhang ZQ. 2012. Let-7c functions as a metastasis suppressor by targeting MMP11 and PBX3 in colorectal cancer. Journal of Pathology 226:544-555.

Harris CC, Ryan BM, and Robles Al. 2010. Genetic variation in microRNA networks: the implications for cancer research. 10:389-402.

John B, Enright AJ, Aravin A, Tuschl T, Sander C, and Marks DS. 2015. Correction: Human MicroRNA Targets. Plos Biology 3:e264.

Kim KJ, and Cho SB. 2010. Exploring Features and Classifiers to Classify MicroRNA Expression Profiles of Human Cancer. 17th International Conference-Neural Information Processing. Models and Applications:234-241. 
367

368

369

370

371

372

373

374

375

376

377

378

379

380

381

382

383

384

385

386

387

388

389

390

391

392

393

394

395

396

397

398

399

400

401

402

403

404

405

406

407

408

409

410

411

412

413

414

415

416

Landi D, Gemignani F, Naccarati A, Pardini B, Vodicka P, Vodickova L, Novotny J, Forsti A, Hemminki K, and Canzian F. 2013. Polymorphisms within micro-RNA-binding sites and risk of sporadic colorectal cancer. Carcinogenesis 29:579-584.

Lee S, and Vasudevan S. 2013. Post-transcriptional Stimulation of Gene Expression by MicroRNAs. Advances in Experimental Medicine \& Biology 768:97-126.

Lee Y, Jeong S, Hong S, Cho B, Woosong HA, Park S, Choi S, Jung E, Youngtae JU, and Jeong C. 2013. Prognostic value of CAPZA1 overexpression in gastric cancer. International Journal of Oncology 42:1569-1577.

Lewis BP, Shih I-h, Jones-Rhoades MW, Bartel DP, and Burge CB. 2003. Prediction of Mammalian MicroRNA Targets. Cell 115:0-798.

Lin DC, Du XL, and Wang MR. 2010. Protein alterations in ESCC and clinical implications: a review. Diseases of the Esophagus 22:9-20.

Lo WY, Lai CC, Hua CH, Tsai MH, Huang SY, Tsai CH, and Tsai FJ. 2007. S100A8 is identified as a biomarker of HPV18-infected oral squamous cell carcinomas by suppression subtraction hybridization, clinical proteomics analysis, and immunohistochemistry staining. Journal of Proteome Research 6:2143-2151.

Lu J, Getz G, Miska EA, Alvarez-Saavedra E, Lamb J, Peck D, Sweet-Cordero A, Ebert BL, Mak RH, and Ferrando AA. 2005. MicroRNA expression profiles classify human cancers. 435:834-838.

Nohata N, Hanazawa T, Kinoshita T, Okamoto Y, and Seki N. 2013. MicroRNAs function as tumor suppressors or oncogenes: Aberrant expression of microRNAs in head and neck squamous cell carcinoma. Auris Nasus Larynx 40:143-149.

Pennathur A, Gibson MK, Jobe BA, and Luketich JD. 2013. Oesophageal carcinoma. Lancet 381:400-412.

Quan L, Xiang-Mei Q, Qing-Han L, Xiao-Yan W, Li L, Min X, Min D, and Yan-Bing X. 2015. MicroRNA-424 may function as a tumor suppressor in endometrial carcinoma cells by targeting E2F7. Oncology reports 33:2354-2360.

Ravegnini G, Serrano C, Simeon V, Sammarini G, Nannini M, Roversi E, Urbini M, Ferrè F, Ricci R, and Tarantino G. 2019. The rs 17084733 variant in the KIT 3' UTR disrupts a miR-221/222 binding site in gastrointestinal stromal tumour: a sponge-like mechanism conferring disease susceptibility. Epigenetics 14:545-557.

Sethupathy P, and Collins FS. 2008. MicroRNA target site polymorphisms and human disease. Trends in Genetics 24:489-497.

Shi M, Han W, and Spivack SD. 2013. A quantitative method to identify microRNAs targeting a messenger RNA using a 3'UTR RNA affinity technique. Analytical Biochemistry 443:112.

Song Y, Li L, Ou Y, Gao Z, Li E, Li X, and Zhang W. 2014. Identification of genomic alterations in oesophageal squamous cell cancer. Nature 509:91-95.

Tang Y, Meng X, Yu X, Shang H, Chen S, Liao L, and Dong J. 2019. Inhibition of microRNA875-5p promotes radioiodine uptake in poorly differentiated thyroid carcinoma cells by upregulating sodium-iodide symporter. Journal of Endocrinological Investigation. 43:439-450.

Tsugawa H, Mori H, Matsuzaki J, Sato A, Saito Y, Imoto M, Suematsu M, and Suzuki H. 2018. CAPZA1 determines the risk of gastric carcinogenesis by inhibiting Helicobacter pylori CagA-degraded autophagy. Autophagy. 15:242-258.

Wang J, Lu Y, Ding H, Gu T, and Ma C. 2017. The miR-875-5p inhibits SATB2 to promote the invasion of lung cancer cells. Gene 644:13-19.

Wang L, Wei L, Wei J, Jing L, Yongdong J, Bo L, Da P, and Peristera P. 2012. A miRNA Binding Site Single-Nucleotide Polymorphism in the 3'-UTR Region of the IL23R Gene Is Associated with Breast Cancer. Plos One 7:e49823.

Peer] reviewing PDF | (2020:03:46920:3:0:NEW 2 Dec 2020) 
417 Wei L, Zhou Q, Hou S, Bai L, Liu Y, Qi J, Xiang Q, Zhou Y, Kijlstra A, and Yang P. 2014. MicroRNA-146a and Ets-1 Gene Polymorphisms Are Associated with Pediatric Uveitis. Plos One 9: e91199.

Wynendaele J, Böhnke A, Leucci E, Nielsen SJ, and Bartel F. 2010. An Illegitimate microRNA Target Site within the 3'UTR of MDM4 Affects Ovarian Cancer Progression and Chemosensitivity. Cancer Research 70:9641-9649.

Xiong F, Wu C, Chang J, Yu D, Xu B, Yuan P, Zhai K, Xu J, Tan W, and Lin D. 2011. Genetic Variation in an miRNA-1827 Binding Site in MYCL1 Alters Susceptibility to Small-Cell Lung Cancer. Cancer Research 71:5175-5181.

Yu F, Zhu X, Feng C, Wang T, Hong Q, Liu Z, and Tang S. 2011. Proteomics-based identification of spontaneous regression-associated proteins in neuroblastoma. Journal of Pediatric Surgery 46:1948-1955.

Zhang L, Liu Y, Song F, Zheng H, Hu L, Lu H, Liu P, Hao X, Zhang W, and Chen K. 2011. Functional SNP in the microRNA-367 binding site in the 3I"UTR of the calcium channel ryanodine receptor gene 3 (RYR3) affects breast cancer risk and calcification. Proceedings of the National Academy of Sciences of the United States of America 108:13653-13658.

Zhang T, Cai X, Li Q, Xue P, and Xue Y. 2016. Hsa-miR-875-5p exerts tumor suppressor function through down-regulation of EGFR in colorectal carcinoma (CRC). Oncotarget 7:42225-42240. 


\section{Figure 1}

miR-875-5p promoted cell proliferation, migration and invasion of ESCC cells

(A) miR-875-5p encoding gene exhibits $6 \%$ and $5 \%$ amplification, while which was about $1 \%$

deletion in EAC and ESCC from TCGA and cBioProtal for Cancer Genomics database. (B, C) NC and miR-875-5p mimics were transfected into KYSE180 cells, then 600 cells were seeded per well in $60 \mathrm{~mm}$ plates and colony formation assays were employed to test the effect of miR-875-5p on ESCC cell proliferation. (D) Data analysis of colony numbers of NC and miR-875-5p in KYSE180 cells, which were relative to miR-875-5p. (E, F) Colony numbers of KYSE510 cells. (G) Statistical analysis of colony numbers in KYSE510 cells. (H, I) Transwell assays were performed to detect the effect of NC and miR-875-5p on KYSE180 cell migration. (J) Data analysis of migration in KYSE180 cells. (K, L) Transwell assays were employed to measure the influence of NC and miR-875-5p on KYSE180 cell invasion. (M) Statistical analysis of invasive cell numbers of NC and miR-875-5p in KYSE180 cells. (N, O) Migrating ability of KYSE510 cells. (P) Data analysis of migration in KYSE510 cells. (Q, R) Invasive ability of KYSE510 cells. (S) Statistical analysis of invasive cell numbers of KYSE510 cells. All experiments were performed at least three times and data were statistically analysed by Student's t-test (two-tailed). ${ }^{*} p<0.05, * * p<0.01$ and ${ }^{* * *} p<0.001$. Error bars indicate standard deviation (SD). 

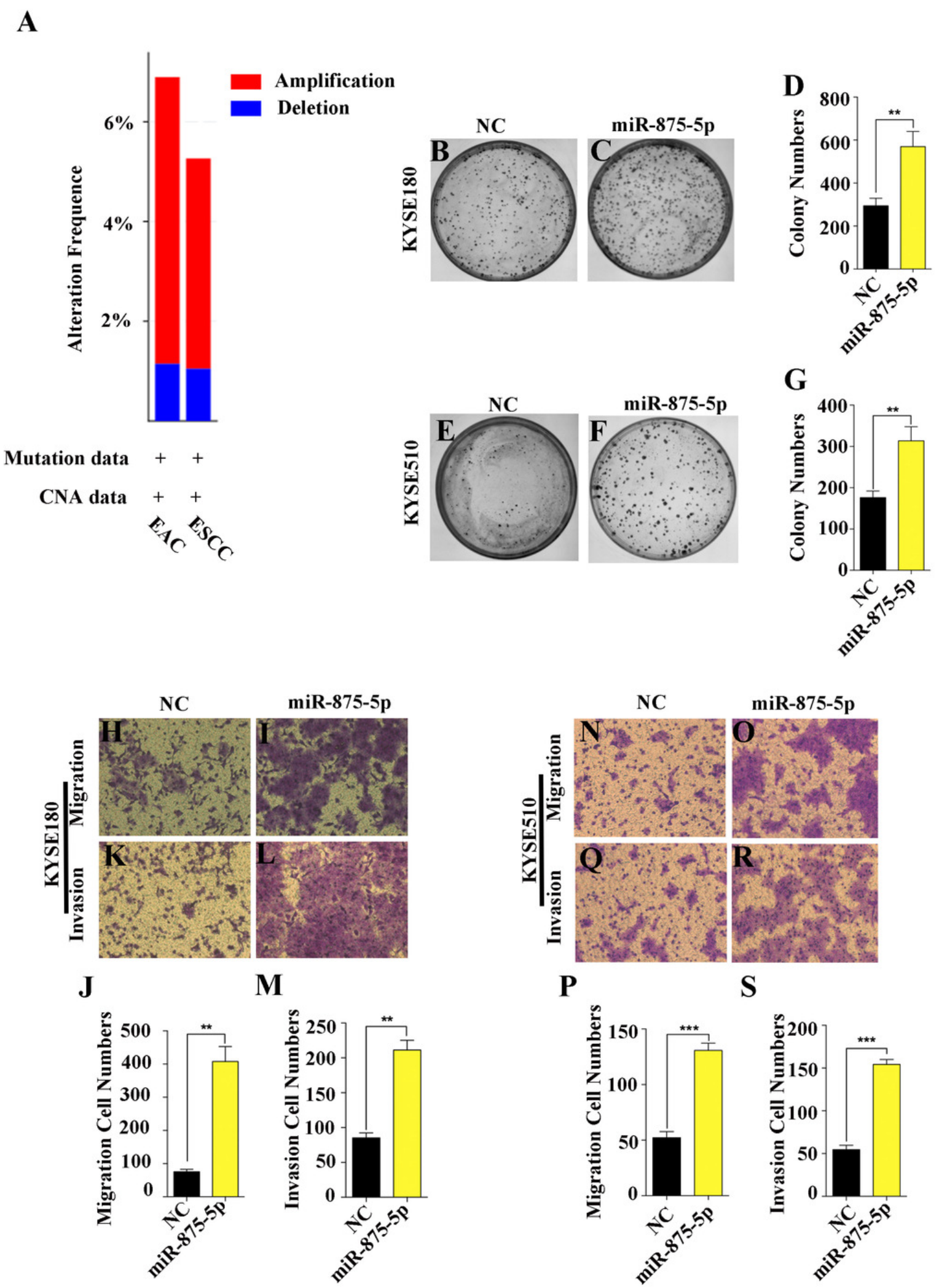

S

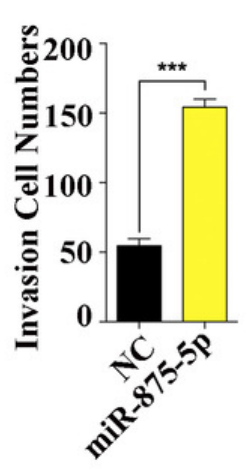




\section{Figure 2}

Identification of miR-875-5p base pairing with CAPZA1 (T)

(A) The sequence of miR-875-5p targeting to seed region of CAPZA1 3'UTR containing the reference allele (red). (B) The location of CAPZA1 in genome and its single nucleotide variation in $3^{\prime} U T R$. (C) Sequencing of CAPZA1 in ten ESCC cell lines. (D) The construct of pGL3-CAPZAI(T) and $p G L 3-C A P Z A 1(G)$ containing Renilla luciferase gene and full-length 3'UTR of CAPZA1 gene. (E) pGL3-CAPZA1(T) and pGL3-CAPZA1(G) were co-transfected in parallel with NC and miR-875-5p mimic into KYSE180 cells and luciferase activity was performed to measure the targeting of miR-875-5p to CAPZAI(T) and CAPZAI(G). Luciferase activity was measured and normalized to firefly luciferase. All experiments were performed at least three times and data were statistically analysed by two-tailed t-test. ${ }^{* *} p<0.01$. Error bars indicate SD. 
A
5'UTR
CDS
3'UTR

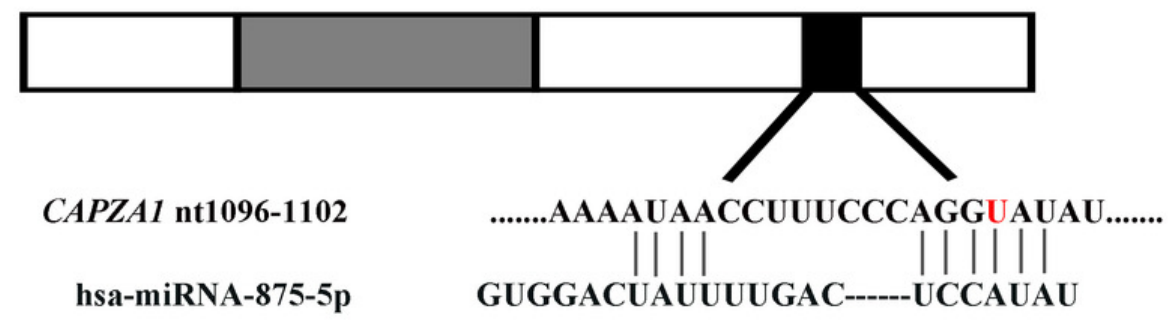

B

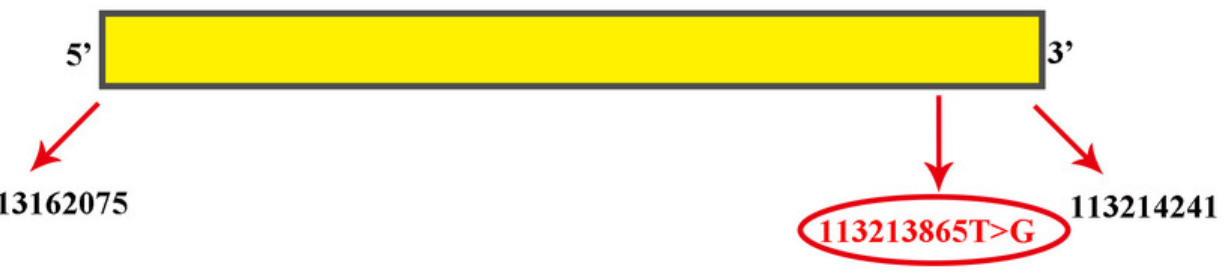

C

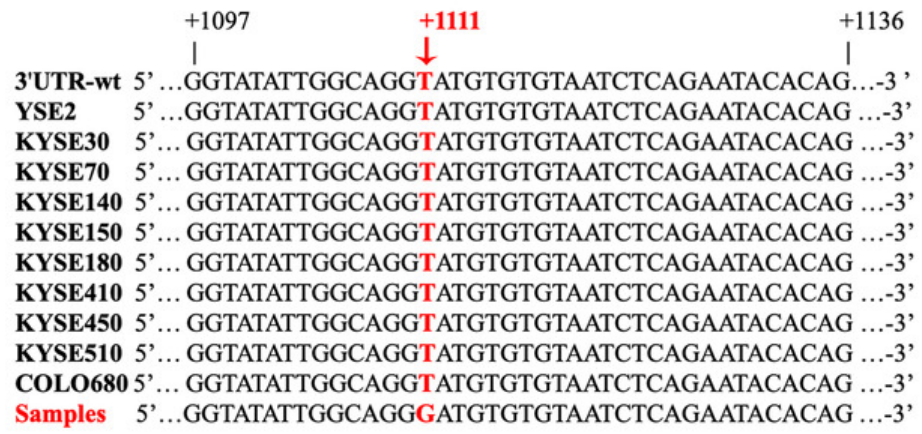

D

SV40 promoter

Luciferase

pGL3-CAPZA1(T)

SV40 promoter

Luciferase

pGL3-CAPZA1(G)
$\mathbf{E}$

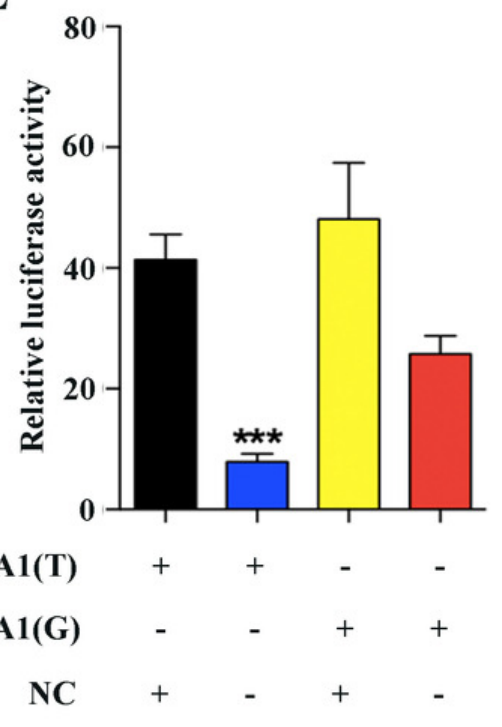

miRNA mimic 


\section{Figure 3}

CAPZA1(T) decreased the proliferation of ESCC cells and the function of CAPZA1 CDS was not reversed by the mimic of miR-875-5p

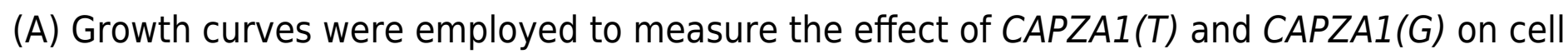
proliferation in KYSE180 cells. (B) Growth curves were performed to measure the cell proliferation ability in stably overexpressed CAPZA1(T) and CAPZA1(G) KYSE510 cells. (C, D and E) 600 cells were seeded per well in $60 \mathrm{~mm}$ plates and colony formation assays were employed to detected the effect of cell growth in stably overexpressed CAPZA1(T) and CAPZA1(G) KYSE180 cells. (F) Data analysis of colony numbers of control vector, CAPZA1(T) and $\operatorname{CAPZAI}(G)$ in KYSE180 cells, which were relative to CAPZAI(T). (G, H and I) 600 cells were seeded per well in $60 \mathrm{~mm}$ plates and colony formation assays were performed to test the influence of CAPZA1(T) and CAPZA1(G) on cell growth in KYSE510 cells. (J) Data analysis of colony numbers of KYSE510 cells. (K) Growth curves were selected to detect the function of CAPZA1 CDS in KYSE180 cells. (L, M) 600 cells were seeded per well in $60 \mathrm{~mm}$ plates and colony formation were performed to detect the cell proliferation of control vector and CAPZA1 CDS in KYSE180 cells. (N) Data analysis of colony numbers in KYSE180 cells. (O) Growth curves were employed to assess whether the cell proliferation of CAPZA1 CDS was reversed by miR-875-5p in KYSE180 cells. (P, Q) 500 cells were seeded per well in $60 \mathrm{~mm}$ plates and colony formation were performed to measure cell growth ability of CAPZA1 CDS and CDS+miR-875-5p in KYSE180 cells. (R) Statistical analysis of colony numbers in KYSE180 cells. All experiments were performed at least three times and data were statistically analysed by ANOVA and Student's t-test (two-tailed). ${ }^{*} p<0.05$, ${ }^{* *} p<0.01$ and ${ }^{* * *} p<0.001$. Error bars indicate SD. 
A

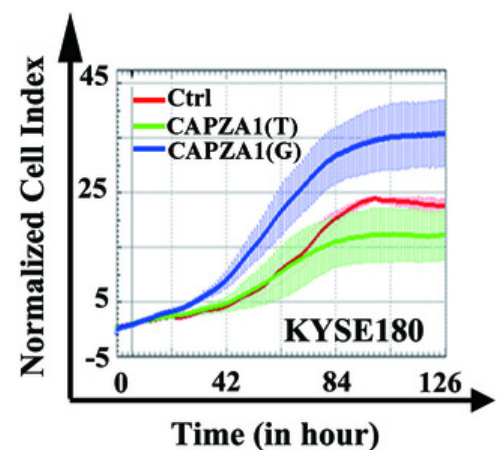

Time (in hour)

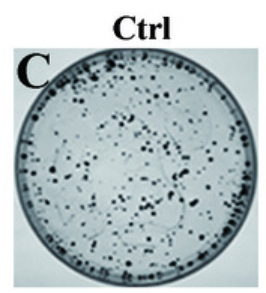

$\mathbf{F}$

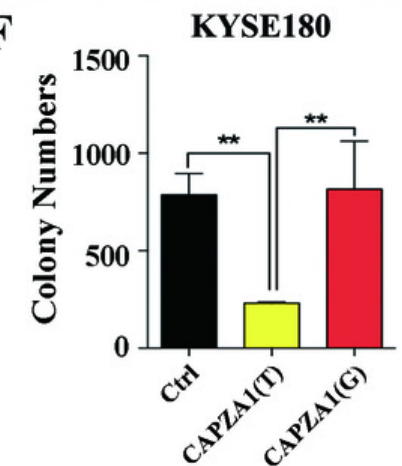

$\mathbf{K}$
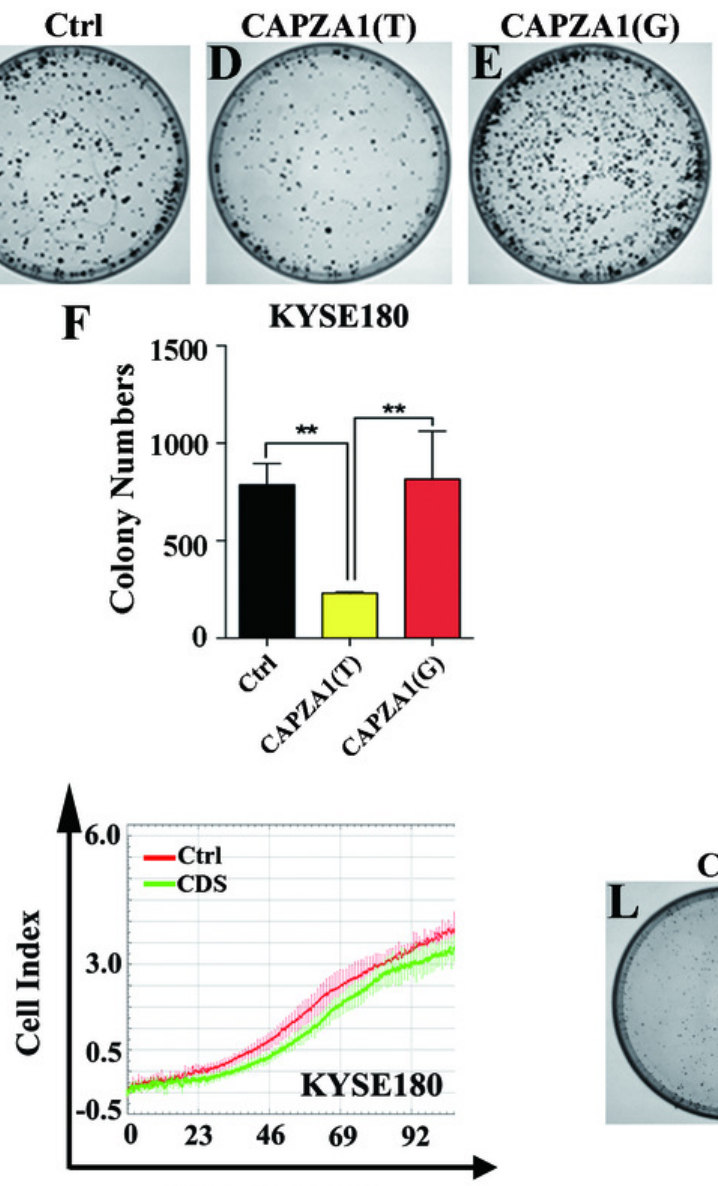

Time (in hour)

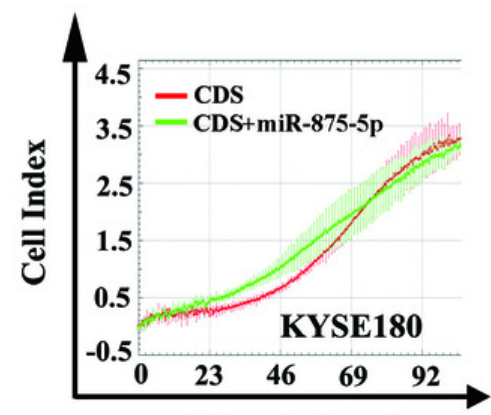

Time (in hour)
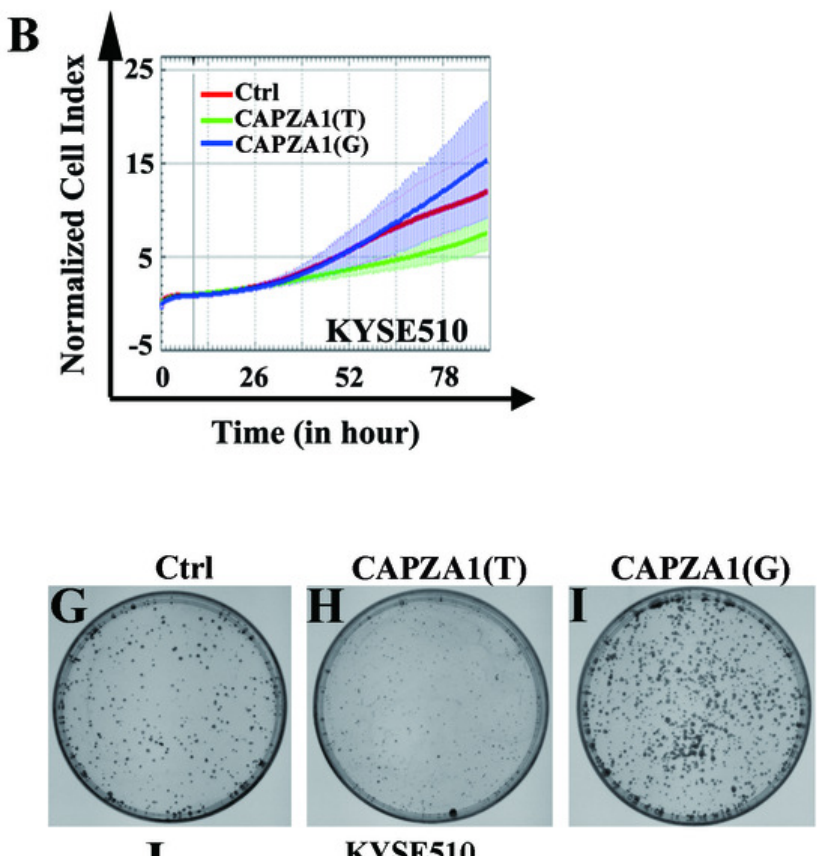

J
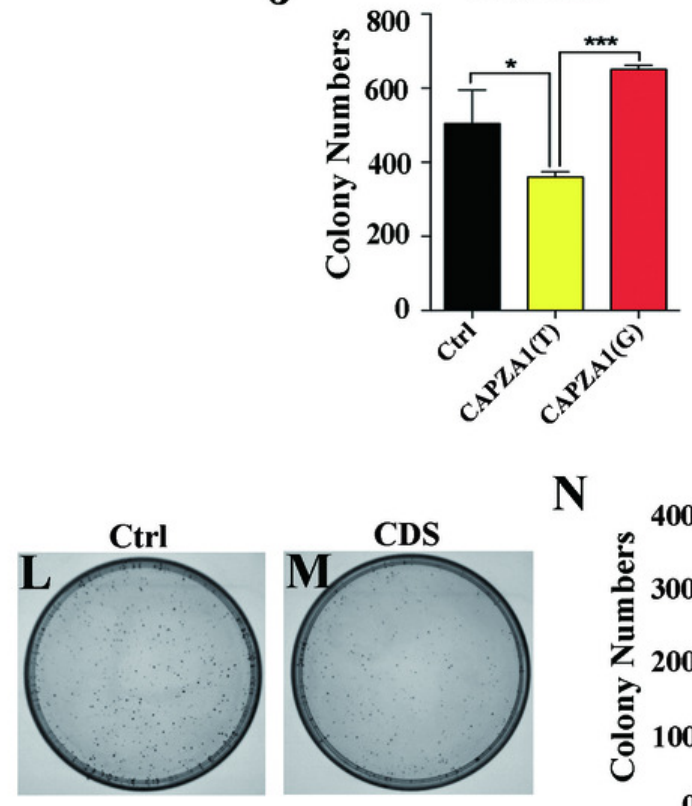

$\mathbf{N}$

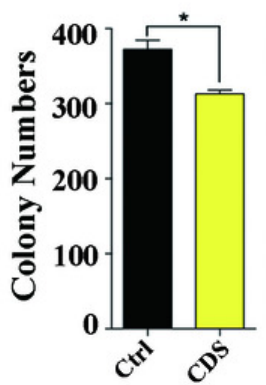

$\mathbf{R}$
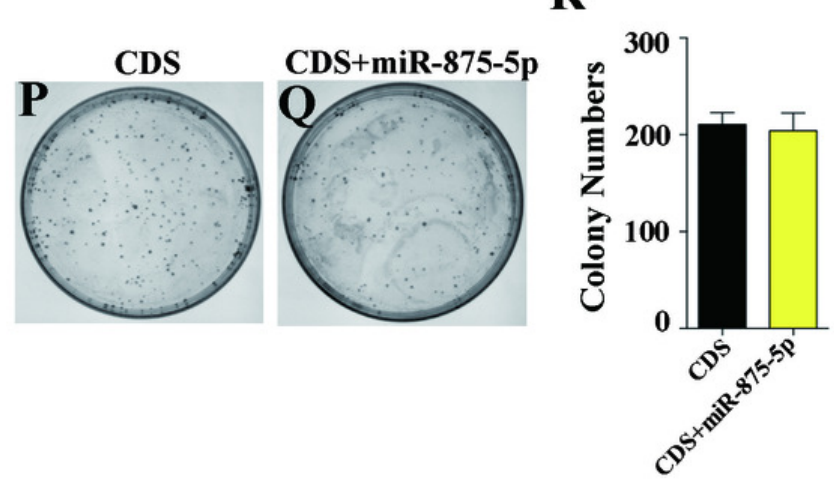


\section{Figure 4}

miR-875-5p targeted CAPZA1(T) and negatively regulated CAPZA1 expression

(A) CAPZA1(T) and CAPZA1(G) plasmids were co-transfected with miR-875-5p mimic into KYSE180 cells and western blotting assays were performed to measure the regulation of miR-875-5p on the protein levels of CAPZA1(T) and CAPZA1(G) in KYSE180 cells. (B) Western blotting assays were performed to measure the regulation of miR-875-5p on $\operatorname{CAPZA1}(T)$ and CAPZA1(G) protein levels in KYSE510 cells. (C) qPCR assays were performed to assess the regulation of miR-875-5p on CAPZA1(T) and CAPZA1(G) mRNA levels in KYSE180 cells. (D) qPCR analysis of the regulation of miR-875-5p on CAPZA1(T) and CAPZA1(G) in KYSE510 cells. All experiments were performed at least three times and data were statistically analysed by ANOVA. ${ }^{* * *} p<0.001$. Error bars indicate SD. 
A

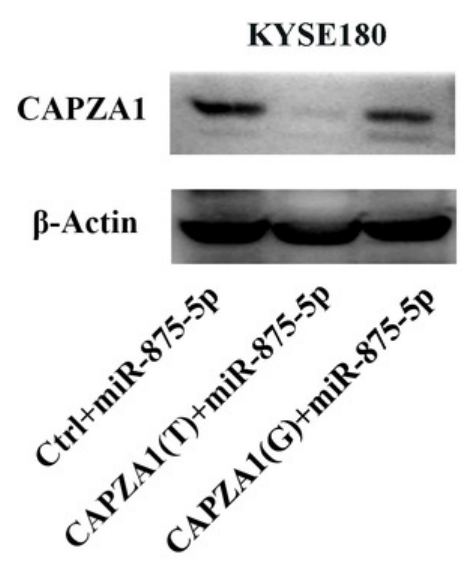

C

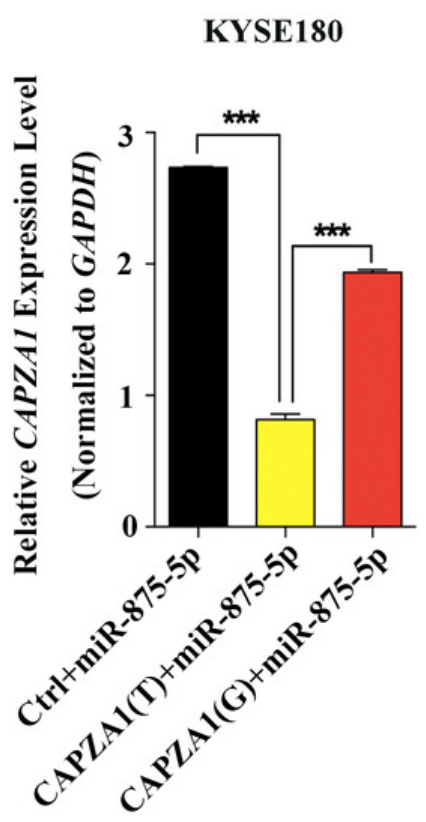

B

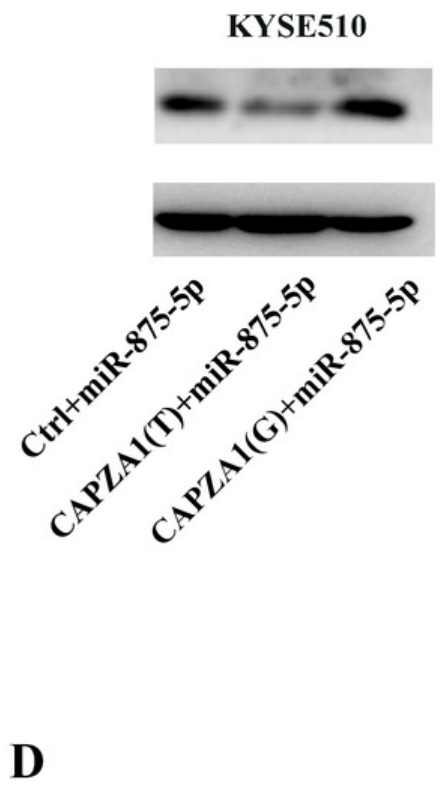

KYSE510

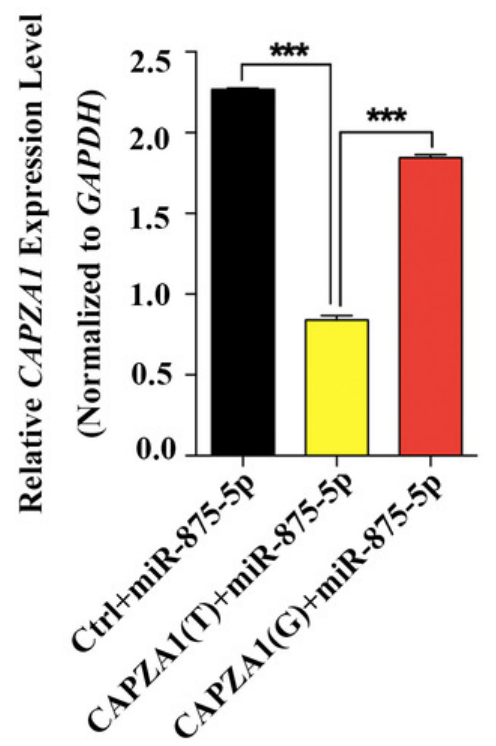




\section{Figure 5}

Association of miR-875-5p with CAPZA1 mRNA

(A) Levels of CAPZA1 mRNA pulled down by biotin-miR-875-5p were measured by qPCR in KYSE180 cells, and in KYSE510 cells (B). (C) The levels of input CAPZA1 mRNA measured by qPCR in KYSE180 cells. (D) Levels of input CAPZA1 mRNA in KYSE510 cells. (E) The enrichment of $C A P Z A 1(T)$ and $C A P Z A 1(G)$ mRNA pulled down by miR-875-5p were measured by $q P C R$ in KYSE180 cells. (F) The enrichment of CAPZA1 mRNA in KYSE510 cells. The enrichment of CAPZA1 mRNAs binding to miR-875-5p was calculated as follows: miRNA pulldown/control pull-down $(X)$, miRNA input/control input $(Y)$, enrichment of CAPZA1 mRNAs = $X / Y$. Representative bar diagram from three independent experiments, each set of experiment was done in triplicates. Error bars mean SD and asterisk stands for statistically significant based on two-tailed Student's t-test where $p<0.05$. 
A

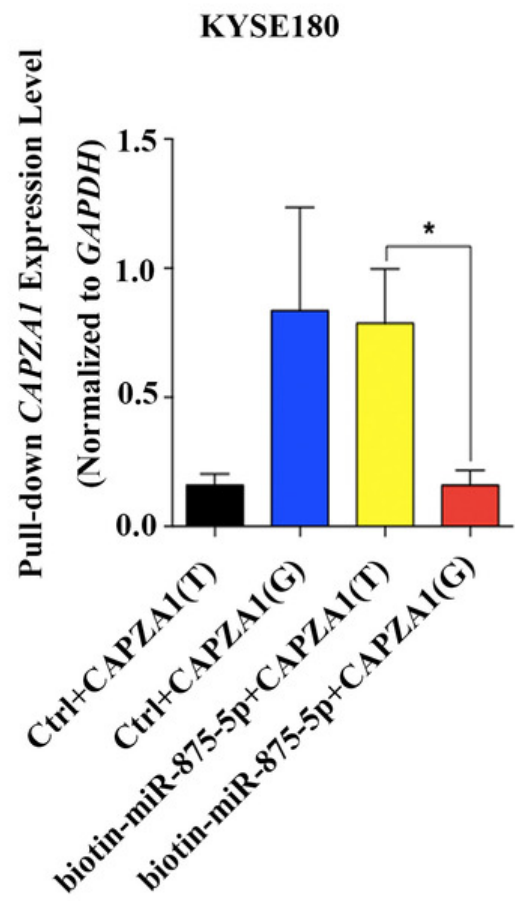

B

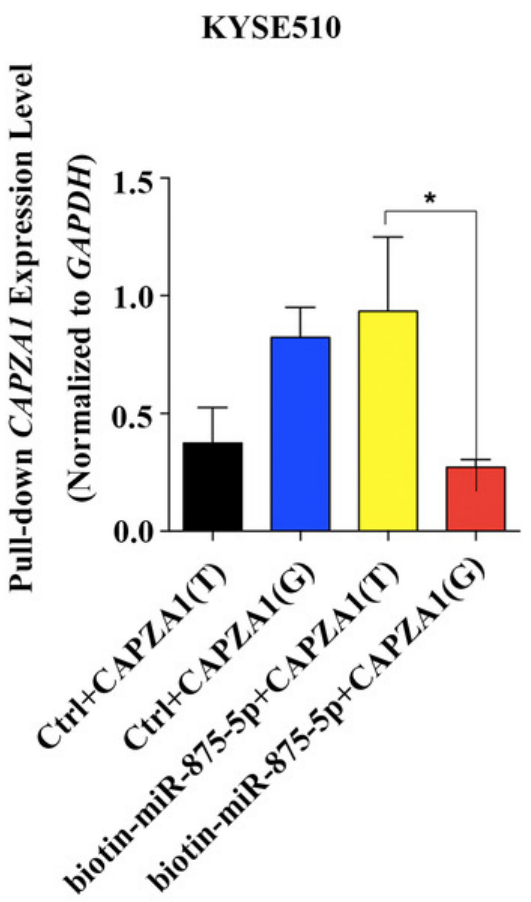

C
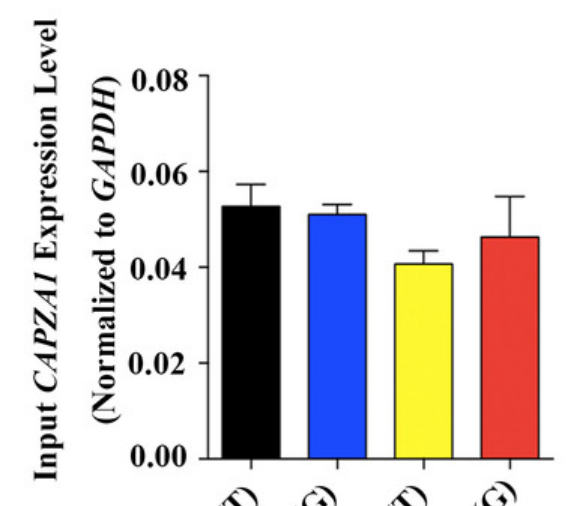

KYSE180

E

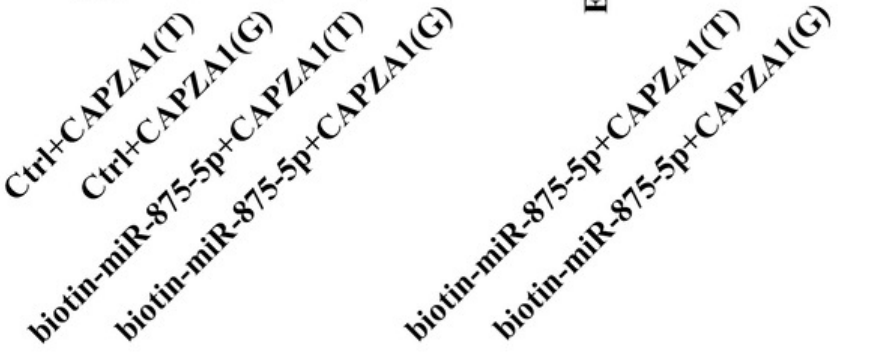

D

KYSE510

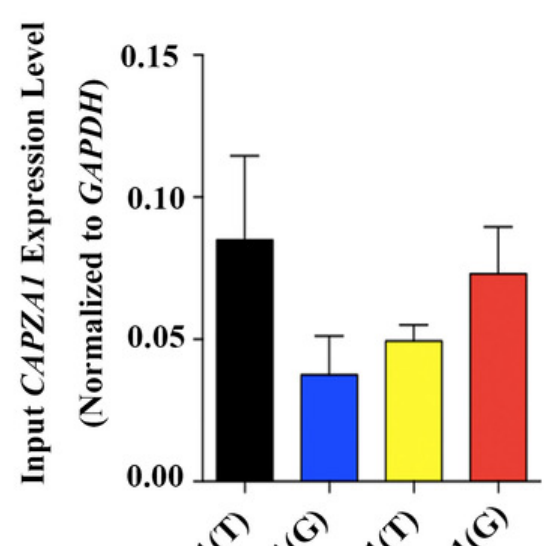

KYSE510
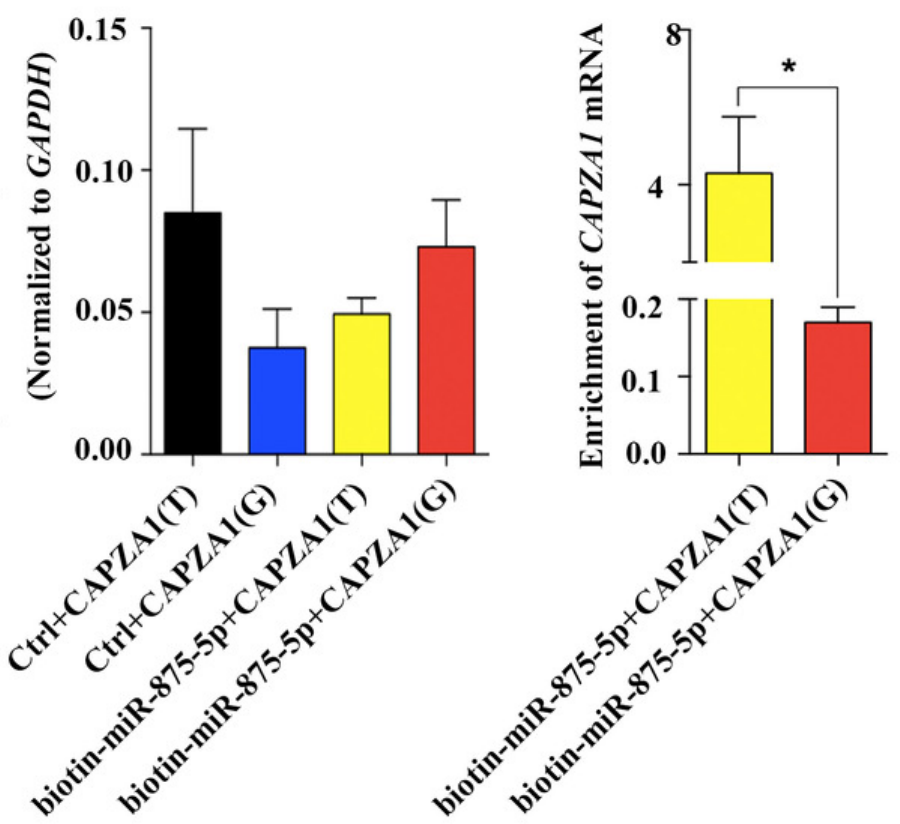